\title{
Getting a Bigger Bang for Your Buck: A Collaborative Approach to Enhancing Dementia Education Planning in Long-Term Care Homes
}

\section{En avoir plus pour son argent : collaboration pour améliorer la planification de la formation en matière de démence dans les établissements de soins de longue durée}

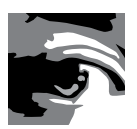

by CARRIE A. MCAINEY, PHD

Assistant Professor, Department of Psychiatry and Behavioural Neurosciences McMaster University

Evaluation Consultant and Seniors' Health Initiative Lead, Hamilton Family Health Team Director of Evaluation and Research, Geriatric Psychiatry Service, St. Joseph's Healthcare Hamilton, ON

LORETTA M. HILLIER, MA

Research and Evaluation Consultant

London, ON

MARGARET RINGLAND, RN, BSCN

Former Director, Member Relations and Professional Services

Ontario Association of Non-Profit Homes and Services for Seniors

Woodbridge, ON 
Carrie A. McAiney et al.

NANCY COOPER, MHSA

Director, Policy and Professional Development

Ontario Long-Term Care Association

Markham, ON

EDUCATION FOR HEALTHY AND SAFE PLACES

TO LIVE AND WORK COLLABORATIVE GROUP ${ }^{1}$

\begin{abstract}
A collaborative of Ontario-based long-term care associations, researchers, clinicians and educators representing various education initiatives related to dementia care and challenging behaviours used existing research evidence on adult learning principles, knowledge transfer and performance improvement to develop an evidence-based approach to support practice change and improvement in long-term care. The collaborative was led by the two provincial long-term care associations with no external funds to support its activities. This effort illustrates how people with common challenges, visions and goals can work together to share their intellectual and physical resources to address pervasive problems.
\end{abstract}

\title{
Résumé
}

Une collaboration ontarienne entre associations, chercheurs et cliniciens ouvrant dans les soins de longue durée, ainsi que des éducateurs représentants des initiatives de formation en matière de démence et de comportements difficiles, utilise les données de recherches actuelles sur les principes d'apprentissage des adultes, le transfert de connaissances et l'amélioration du rendement pour développer une démarche fondée sur les données probantes afin d'appuyer les changements dans la pratique et l'amélioration des soins de longue durée. Cette collaboration a été dirigée par les deux associations provinciales de soins de longue durée, sans financement externe pour appuyer leurs activités. Cette initiative montre comment les personnes confrontées à des défis, à des visions et à des objectifs similaires peuvent travailler de concert afin de partager les ressources intellectuelles et physiques pour traiter des problèmes récurrents.

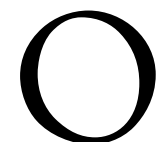

VER HALF OF OLDER PERSONS WITH DEMENTIA LIVE IN LONG-TERM CARE

(LTC) homes (Canadian Study of Health and Aging Working Group

1994). It is commonly accepted that up to $90 \%$ of patients with dementia develop behavioural problems (physical or verbal aggression, or both) or psychiatric symptoms at some point (Braun and Kunik 2004; Brodaty et al. 2001). LTC homes are challenged to meet the needs of this increasingly complex resident population. 


\section{Getting a Bigger Bang for Your Buck: A Collaborative Approach to Enhancing Dementia Education Planning in Long-Term Care Homes}

Healthcare aides and personal support workers provide $70 \%$ of direct resident care in LTC homes (Health Professions Regulatory Advisory Council 2006). In Ontario, training certificate programs for healthcare aides and personal support workers have been offered through community colleges, private colleges and boards of education since the early 1980s. However, this minimal training in nursing support roles no longer equips these key front-line staff with the skills to meet the complex needs of the current resident population of LTC homes (Stolee et al. 2005).

There is much support for increased education for LTC staff (American Geriatrics Society and American Association for Geriatric Psychiatry 2003; Fitzpatrick 2002). In addition to ongoing staff education, LTC homes often turn to continuing education (CE) when faced with compliance citings related to Ministry of Health standards, a critical incident, accreditation, policy planning, or continuous quality improvement (CQI) related to prevention, risk management or enhancement of quality of life. While recent research indicates that $96 \%$ of personal support workers believe there is a need for work-related training, there are many challenges associated with a $\mathrm{CE}$ approach to increasing staff capacity in terms of knowledge and skills to improve healthcare (Brookman 2007). Generally, there is minimal evidence of sustained knowledge transfer (practice change) in LTC homes following CE (Aylward et al. 2003). Only in the past few years has attention been paid in LTC homes to the factors known to facilitate practice change, such as organizational and management support (Stolee et al. 2005). Administrators are challenged to provide CE because of limited resources, including paying for the education and backfilling positions so that staff can attend. Furthermore, those responsible for selecting educational programs for their staff have a multitude of programs to choose from, such that they have difficulty deciding which ones will be most effective in meeting their needs to improve resident care.

These challenges were well known to two major Ontario-based LTC associations: the Ontario Association for Non-Profit Homes and Services for Seniors (OANHSS) and the Ontario Long-Term Care Association (OLTCA). With a common vision of improving care for residents with dementia, these two associations partnered to establish a collaborative group consisting of representatives from their own associations and researchers, clinicians, health and safety experts, and educators representing various education and best practice initiatives for dementia care and responsive (challenging) behaviours. Multi-organizational collaboratives have been identified as an effective vehicle for learning about and disseminating best practices, problem-solving healthcare challenges, reducing duplication of services, and building practice capacity (Ermshoff et al. 2007; Marsteller et al. 2007; Øvretveit et al. 2002). Interagency collaboration in this instance was facilitated by individuals involved in different aspects of LTC who collaborated to problem-solve shared dilemmas experienced within the LTC system. Collaboratives, consistent with Communities of Practice (CoPs), have been defined as groups of people who share a common concern and a desire to resolve it (Wenger 
1998). CoPs have been identified as a significant mechanism for improving practice in a number of communities, including family physicians (Endsley et al. 2005), healthcare students (Moule 2006), nurses within geriatric settings (Tolson et al. 2006) and various healthcare agencies (Lathlean and le May 2002). With a common vision of improving care for older persons with dementia, the collaborative (or CoP) described here used existing research evidence on adult learning principles, knowledge transfer and performance improvement to develop an evidence-based approach to support practice change and improvement in LTC.

This paper describes the process undertaken and lessons learned by the collaborative in developing its approach to enhancing CE in LTC.

\section{Knowledge Translation Initiative}

In late 2005, key leadership from OANHSS and OLTCA invited representatives from various educational programs and other key stakeholders (knowledge brokers, representatives from the Ontario Ministry of Health and Long-Term Care, clinicians, workplace safety educators, researchers) to join a collaborative named the Education for Healthy and Safe Places to Live and Work Collaborative Group. ${ }^{1}$ Although the collaborative initially aimed to foster awareness and communication regarding educational programs available to LTC homes in Ontario, following lengthy discussions about the role and impact of education in LTC homes, it was acknowledged that education in and of itself would not resolve performance issues or change practice. Bolstered by the notion of fostering learning environments in which $\mathrm{CE}$ is but one strategy for enhancing capacity, this group moved forward to develop a tool to support LTC homes in their decision-making regarding staff education and development.

TABLE 1. Timeline of activities leading to the development of the DENA tool

December 2005

- Key stakeholders are invited by OANHSS and OLTCA to a meeting to share and gather information regarding current educational strategies for dementia.

- Plans are developed to create a matrix of available dementia-related programs. Additional key stakeholders are identified. The group formally commits to creating the Education for Healthy and Safe Places to Live and Work Collaborative Group.

February 2006

- Plans are discussed for developing a matrix describing each educational program. There is consensus that program information alone is not sufficient to assist homes in selecting the most appropriate education for their home/situation.

- The group decides to explore the development of an algorithm to assist homes in the education decision-making process. Support of a consultant is recommended.

March 2006

- Consultant retained.

- Key issues related to the tool are articulated, including underlying principles, anticipated outcomes, resources and 


\section{Getting a Bigger Bang for Your Buck: A Collaborative Approach to Enhancing Dementia Education Planning in Long-Term Care Homes}

supports available to facilitate decision-making, indicators for use, target audience and possible formats for the tool.

- Initial design for tool explored.

April - June 2006

- Initial version of tool developed.

June 2006

- Meeting to review and refine the tool. Group decides that current design is not sufficient and decides to use an algorithm to better help LTC homes to determine their needs for education and their capacity to support education.

July 2006

- Algorithm drafted.

August 2006

- Meeting to review and refine the tool. Initial discussion regarding the development of a matrix of education programs and marketing of the tool.

September 2006

- Tool revised.

October 2006

- Meeting to review and further refine the tool and obtain consensus on revisions. Parts I and II of the tool are finalized.

- Consultant support is terminated as members are able to undertake remaining tasks.

November 2006 - February 2007

- Plans to pilot-test tool developed.

- Members develop and refine the educational matrix (Part III).

March - April 2007

- DENA tool pilot-tested by LTC homes.

- Feedback shared with collaborative group. Changes to DENA tool decided.

May - August 2007

- DENA tool finalized.

- Online version of tool developed.

September 2007 - September 2008

- DENA tool marketed at various venues (e.g., OLTCA and OANHSS meetings, Canadian Coalition of Seniors' Mental Health annual meeting, Ontario Ministry of Health and Long-Term Care Innovation Expo, Ontario Safety Association for Community and Healthcare Conference, several Seniors' Health Research Transfer Network (SHRTN) Community of Practice Fireside Chats).

- Tool made available to all LTC homes.

LTC $=$ long-term care

OANHSS = Ontario Association for Non-Profit Homes and Services for Seniors

OLTCA = Ontario Long-Term Care Association

A consultant with expertise in adult education and knowledge transfer was hired to assist the group in developing the tool. Over the course of almost three years, the collaborative met approximately 12 times, sometimes for day-long meetings, to develop the tool; additional work was done on this project between meetings. A timeline of activities leading to the development of the tool is presented in Table 1. Consensus for decision-making regarding development of the tool (components, revisions) was achieved through discussion. 
Integrating knowledge of adult learning principles, knowledge transfer and performance improvement, and based on the collective experience and wisdom of the group, the collaborative first worked to identify key principles that would underlie the development of a decision-making tool for education. As well, this tool would need to address the challenges that LTC homes experience as they attempt to build capacity and improve care. The guiding principles were as follows:

- LTC homes require simple, user-friendly and client-focused tools to facilitate dialogue about existing gaps, strengths and needs for capacity building and education; link homes to available resources; and assist with proactive problem-solving (rather than reactionary decision-making) in a manner that allows homes to assume responsibility for ongoing education planning.

- Many different solutions could be implemented to address the issues that would bring an end-user to this tool; strategies other than CE can build on and support existing capacity to resolve performance gaps. There is much evidence highlighting the factors and strategies that facilitate and reinforce practice change (Broad and Newstrom 1992; Rushmer et al. 2004a,b).

+ LTC homes require a well-thought-out and sustainable education plan. Decisionmaking regarding CE should take into account the organization's need and capacity to support education and should assist homes in determining the supports and strategies that are needed to enhance their capacity to manage specific physical and mental health issues.

- The decision-making process need not be conducted in isolation; various internal and external resources are available for consultation.

\section{Results of the Knowledge Translation Initiative: The Dementia Education Needs Assessment (DENA) Tool}

The collaborative group has developed a practical, evidence-based tool to help decision-makers in LTC homes to develop an action plan for education. As the group met over the course of three years, various formats and versions of the tool were developed and revised.

The purpose of the tool, called the Dementia Education Needs Assessment (DENA) tool, is to assist professionals (e.g., administrators/executive directors, directors of care/services, case managers, educators, clinicians, health and safety committees) working in LTC homes to make decisions about CE programs related to dementia. The tool is designed to assist organizations in supporting practice change and performance improvement through education, and acknowledges that education may not necessarily be the solution to their performance gaps; strategies other than $\mathrm{CE}$ can 
build on and support existing capacity to improve clinical practice. To this end, the tool aims to help users determine whether they need education and are able to support practice change, and if so, to inform them of the available educational opportunities. Although CE can take many forms (e.g., informal, "teaching in the moment" opportunities, case-based learning), this tool focuses on formal education opportunities.

The tool consists of three parts; users are directed to proceed through each part in sequence. Each part consists of a series of questions designed to stimulate reflection and facilitate dialogue about performance gaps and needs for capacity building and education. The questions also link LTC homes to available resources and assists them with proactive problem-solving in a manner that allows them to assume responsibility for their education planning, rather than dictating the educational programs that they should choose. Set up in somewhat of an algorithmic format, users' responses to the various questions guide them through the tool.

\section{Part I: Do you need education?}

This first step of the tool assists users in determining whether education is what their organization currently needs, and provides suggestions for alternative options to build capacity. Four key questions guide users through this section of the tool:

\section{WHAT IS THE ISSUE THAT BRINGS YOU TO THIS TOOL?}

This step engages users to think about the issues that have brought them to the tool. The tool can be used for a variety of purposes, many of which are interrelated. Individuals or groups may find the tool helpful when faced with critical incidents (e.g., resident or staff injury), policy planning, risk management, budgeting and planning for staff development and education, or when trying to make sense of available education programs and determining whether these programs would be beneficial to their staff and residents.

\section{WHAT ARE THE IDENTIFIED GAPS IN PERFORMANCE THAT EXIST IN YOUR} ORGANIZATION?

When considering the gaps in knowledge or skills related to the care of older persons with dementia, tool users are asked to reflect on a few key questions: What are the skills or knowledge that you would like staff to have? What changes in performance would you like? What do you hope to achieve? What commitment to education have you already made in this area, and what has come of it? What remains to be accomplished? The answers to these questions will help users determine whether their organization requires further education, or whether other strategies are needed to build on existing capacity. 
3. WITH WHOM HAVE YOU CONSULTED ABOUT DEMENTIA EDUCATION FOR YOUR ORGANIZATION?

Tool users are encouraged to collaborate with others when making decisions about continuing education and to consider that there is a wealth of knowledge and expertise available to help them with their decision-making. Depending on their particular performance issue or question, they are encouraged to consider consulting with resources both inside and outside their organization. Internal resources would include staff educators, social workers, clinical leadership, physicians and family and resident councils. External resources would include psychogeriatric resource consultants (PRCs), ${ }^{2}$ best practice coordinators' (BPCs) provincial associations or organizations, ${ }^{3}$ specialty geriatric psychiatry outreach programs and local education institutions (colleges and universities). These resources can help users make decisions about $\mathrm{CE}$ and how best to resolve performance gaps.

\section{WHAT OTHER OPTIONS EXIST FOR DEVELOPING CAPACITY IN YOUR ORGANIZATION?}

The underlying premise of the tool is that while some of the issues that bring people to it may be resolved through education, some may require other strategies for capacity building within homes. Tool users are encouraged to consider that they may already have the expertise they need within their organization to resolve existing issues, but may need to consider how best to support and use that expertise, or how they might best support staff to apply to their practice what they have already learned in CE programs. Drawing from the literature on factors known to support performance improvement (Bero et al. 1998; Berta et al. 2005; Broad and Newstrom 1992; Grol and Grimshaw 2003; Rummler and Brache 1990, 1995; Watkins and Marsick 1993), tool users are asked to consider strategies other than education to build on and enhance existing capacity in their organizations. These strategies could include clearly communicated management or leadership support; workplace policies and procedures that encourage practice change; on-the-job reinforcement of new skills (coaching, mentoring, networking); opportunities for staff to learn from one another (observe and model) and work together to solve a common problem or to experiment with new ideas or strategies; and creating a workplace culture that encourages change and new approaches. Finally, tool users are encouraged to consider working with internal and external resources to determine how they might best support, develop and enhance existing capacity in their organization.

\section{Part II: Education Readiness Tool}

When users have determined that education is what their organization needs, the tool then forces them to think about whether their organization is ready for education. 
Getting a Bigger Bang for Your Buck: A Collaborative Approach to Enhancing Dementia Education Planning in Long-Term Care Homes

Drawing from the literature on knowledge transfer, this section of the tool encourages users to consider whether they have the organizational supports and resources in place to promote education and to facilitate practice change, such as standards and policies, supplementary resources, champions for change, favourable organizational climate and effective knowledge transfer strategies. The emphasis of this part of the tool is to reflect on the evidence-based factors that make education optimally effective to facilitate and enhance practice change.

Figure 1 presents the Education Readiness tool. In this section of the DENA tool, users are asked to reflect on the four questions shown in the diagram.

\section{FIGURE 1. Education Readiness tool}

The reflective questions highlight the factors that will increase users' chance of success with education and practice change. This tool is not designed to provide a readiness score with regard to the formal education programs on the program matrix. Rather, the questions offer an opportunity to integrate practice with education. The tool emphasizes the success factors that make education optimally effective.

I. Is your practice environment willing and able to support performance improvement?

\section{Structural Factors}

- Are standards and policies in place to support practice change?

- Are you able to provide needed resources? These include:

- staff coverage

- time to practise

- opportunities to practise

- involvement of other staff

- specific program expectations

(e.g., direct care, staff education)

\section{Social Factors}

- Do you have local champions who can support practice changes?

- Will the existing culture and belief systems in your setting support change?

- Are you willing to support changes in administrative or care process that may be needed to allow for performance improvement?

\section{Economic Factors}

- Do you have the resources to support continuing education? These could include:

- program costs (tuition, travel)

- implementation costs (space, equipment)
2. Do you have potential champions for change?

- Do you have appropriate candidates for education?

- Do they have the necessary knowledge and skills to do this?

- Do they have the personal characteristics to be successful/ effective?

- Do they have good rapport with other staff?

- Are they committed to this?

- Are they interested? Passionate about this?

- Are they able to be a good role model to other staff?

3. What does your
organization think
about evidence-based
practice change?
- Do staff perceive the need
for change?
- Do you have management
- support for this?
Do staff tend to have
negative reactions to new
innovations or practices?
- Do staff tend to be positive
about practice changes?
- What barriers to practice
change exist in your
organization?
- Are these barriers
modifiable?

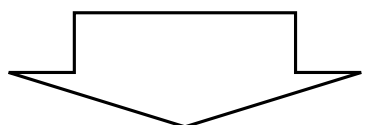

Ready to select a program? Continue to Part III
4. Can your organization support staff in transferring knowledge to practice?

Knowledge Transfer

Strategies

- Do staff have the authority to make practice changes?

- Can they take responsibility for changes?

- Do they have designated time for activities?

- Do they have time to consult/network?

- Do they have access to resources needed to support change?

- Are there clear consequences for knowledge transfer? - reinforcements? - incentives/rewards?

- Will staff get prompt feedback about performance expectations? 

IMPROVEMENT?

There is much literature on the factors that can support use of new knowledge and best practices (e.g., Bero et al. 1998; Berta et al. 2005; Berwick 2003; Broad and Newstrom 1992; Graham and Logan 2004; Rummler and Brache 1990, 1995). These factors are: (a) structural, including the policies, procedures and resources needed to support change, (b) social, including the people (e.g., champions) and attitudes (e.g., organizational culture) needed to support change and (c) economic, including the financial resources associated with providing education (e.g., tuition, travel) and implementing care approaches/strategies stemming from the education (e.g., space, equipment). In the absence of these factors, organizations will be challenged to optimize staff efforts to apply what they have learned in education programs to their clinical practice.

\section{DO YOU HAVE POTENTIAL CHAMPIONS FOR CHANGE?}

Change champions have been identified as critical for quality improvement in LTC homes (Scalzi et al. 2006). With limited resources for CE, the selection of appropriate candidates for education can maximize and sustain the benefits of education through ongoing modelling and teaching with other staff. Their attitudes, confidence, ability and aptitude, personality and relationship with other staff affect their ability to inspire others to transfer learning to clinical practice and improve care (Broad and Newstrom 1992; Hogan and Logan 2004).

\section{WHAT DOES YOUR ORGANIZATION THINK ABOUT EVIDENCE-BASED PRACTICE CHANGE?}

Organizational support for innovation, learning and practice change, at both the staff and management level, are necessary for practice change (McAiney et al. 2007; Stolee et al. 2005). Staff are more likely to engage in new practice activities when they perceive a need for change, have management support and have an organizational culture that values learning and innovation and actively seeks to identify and modify barriers to practice change.

\section{CAN YOUR ORGANIZATION SUPPORT STAFF IN TRANSFERRING KNOWLEDGE TO PRACTICE?}

Support for practice change is evident in the strategies that organizations engage in to facilitate performance improvement. Knowledge transfer strategies include ensuring that staff have the authority and ability to take responsibility for implementing care approaches/strategies learned in CE programs, as well as adequate resources to implement practice change such as time, equipment, space and tools (Rushmer et al. 2004a, 
b). They also include ensuring that factors known to support transfer of learning to performance are in place, such as clear performance expectations as articulated in policies and procedures; clear consequences for practice change (reinforcement, incentives, rewards); and prompt feedback related to how well performance matches expectations (Rummler and Brache 1995).

As users are led through this section of the tool, they need to decide whether or not they are "ready" for education. When they determine that their organization is not able to support education, tool users are led to reconsider the resources they already have for assistance (in-house expertise, external resources); the commitments they have already made to education initiatives; the education staff have already completed; and exploration of other options for developing capacity in their organization. When users have concluded that their organization is ready for education - that is, they have the resources, potential change agents and organizational climate to support CE they are led to Part III of the tool, a matrix of available education programs.

\section{Part III: Selecting the most appropriate education for your organization}

Part III of the DENA tool consists of a matrix of dementia-related education programs available to LTC homes in Ontario. This matrix provides information regarding the goals of the program, the target learner, method of delivery, teachers/trainers, length of training, cost and partners in delivery. The educational programs included in the matrix were suggested by the members of the Education for Healthy and Safe Places to Live and Work Collaborative Group. The collaborative used these programs in the conceptualization, development and testing of the DENA tool. Users are encouraged to apply DENA to support decision-making in relation to any dementiarelated educational programs they are considering.

From the matrix, tool users select the most appropriate program for their organization, depending on the outcomes that they hope to achieve, the group(s) they want to target for education and their preferred educational format(s) (e.g., e-learning, classroom-based).

The DENA tool was pilot-tested in several LTC homes in the province and revised based on feedback received. Members of the Collaborative Group were asked to identify LTC homes that might be willing to pilot-test the tool. In identifying sites, members were asked to consider homes of different sizes from all parts of the province, and from both rural and urban areas. Contact people from the identified homes were sent an e-mail that described the initiative and DENA, and were invited to pilot-test the tool. Those that were interested in piloting the tool were asked to think of a recent situation in their home that prompted them to consider further education as a response. With that situation in mind, the pilot sites were asked to go through the DENA tool. They were then asked to complete an online survey in which they 
described the ease or difficulty of using each part of the tool, its potential value and the time required to complete each section.

Twelve LTC homes pilot-tested the tool and completed the survey. Three-quarters of the respondents indicated that their homes were in a rural area. Homes were located in the central, south and eastern parts of the province. None of the homes were from northern Ontario. The average number of beds in the pilot sites was 138 ( $\mathrm{SD}=26.4$ ), ranging from 100 to 192 beds. Respondents' roles included directors of care $(50 \%)$, educators (33\%), administrators $(8 \%)$ and nurse consultants ( $8 \%$ ).

Overall, feedback on the tool was positive. Eleven of the 12 homes indicated that they would use DENA again to assist them in making decisions about the need for dementia education, and eight of the 12 thought that DENA could assist with education-related decisions in other areas. The pilot sites identified aspects of the tool that they would like changed, most notably the desire to remove the keyword search table, as most found this component of the tool confusing. The feedback on the tool was summarized and shared with the Collaborative Group. The tool was revised and finalized based on the feedback received.

Since finalization of the tool, the Collaborative Group has worked to promote and market it at various venues. An online version as well as an e-learning module were also developed (see www.denatool.org). The tool is available to all LTC homes in the province, as well as any other interested organization or group.

\section{Lessons Learned}

This collaborative was successful in its efforts to develop a tool to help LTC homes address pervasive challenges related to $\mathrm{CE}$ and performance improvement. A collaborative, participatory approach involving LTC associations, researchers, clinicians and other key stakeholders can provide an opportunity to marry research evidence and clinical experience to create effective knowledge translation. The success of this collaborative is related to factors inherent in CoPs, namely, the existence of a common goal, of both tacit (experience) and explicit (evidence) knowledge, and of important relationships among those in the group and with those outside it (Lathlean and le May 2002; Sandars and Heller 2006). Consistent with factors known to support CoPs, the collaborative described here was supported by identified leadership (i.e., LTC associations), regularly scheduled meetings and a high degree of networking among members (Lathlean and le May 2002). Moreover, members' respective agencies/organizations contributed their expertise and provided the necessary time and resources to participate in this initiative. Despite representatives from the educational programs having vested interests in promoting their own formats, the common vision of enhancing care for older persons with dementia in LTC homes drove the collaborative effort. As sug- 
Getting a Bigger Bang for Your Buck: A Collaborative Approach to Enhancing Dementia Education Planning in Long-Term Care Homes

gested by Lathlean and le May (2002), CoPs can serve to break down interagency and interprofessional barriers and boundaries.

Initially, the Collaborative Group focused on developing communication strategies regarding available education programs; the move towards developing this decisionmaking tool required the recognition and acknowledgement of the limitations (e.g., human resources, operational practices, financial resources) that exist within LTC homes, as well as the need to support leaders in their quest to increase staff capacity to enhance care (Bradley et al. 2003; Rushmer et al. 2004b). The group recognized early that, owing to time constraints and workload issues, no one person in the group was able to lead the development of the tool in a timely fashion; a facilitator was therefore hired to help the group move the initiative forward. As the tool was being developed, there were some discussions about which key components should be included, with some members identifying priorities not necessarily shared by all members. The emphasis on using evidence to guide the development of the tool helped to resolve these issues.

The online version of DENA is housed on the Alzheimer Knowledge Exchange (AKE) website; the AKE has assumed responsibility for developing the online version within existing resources. Although the tool can be located on the Internet when searched for by name, it is currently not searchable by topic. While creating a searchable domain would increase accessibility, it could prove costly and, in the absence of resources for this project, may be beyond the capacity of the collaborative at this time.

This collaborative illustrates that resolution of common challenges can be achieved with minimal resource allocation. There was no external support for this initiative; all activities were undertaken with existing resources and in-kind contributions from the various members (e.g., representation from various organizations at the meetings). OANHSS and OLTCA pooled resources to hire the facilitator (cost: $\$ 5,600.00)$. Meeting and teleconference costs were approximately $\$ 2,500$ (roughly $\$ 210$ per meeting for 12 meetings), with meetings held at the OLTCA offices. The costs associated with posting the tool online, and development of the DENA e-modules (software and development), including the creation of a logo and look for the tool, were an in-kind contribution of $\$ 600$ from the Alzheimer Knowledge Exchange (Alzheimer Society of Ontario). In addition, each participant spent much time working on the initiative between meetings, particularly during the development of the education matrix, reflecting in-kind contributions from their respective organizations.

Next steps include the development of sustainability strategies. The feasibility of including other programs in the matrix will need to be assessed. How and by whom the tool will be evaluated on an ongoing basis will also need to be determined. Opportunities to test the tool in other health sectors and settings should be explored further. 


\section{Conclusion}

The development of the DENA tool illustrates how individuals within a CoP who have shared challenges, visions and goals can work together in a collaborative to share their intellectual and physical resources to problem-solve timely and pervasive problems. The DENA tool represents a creative method of informing LTC homes of what is known about how to facilitate practice change (i.e., the supports and resources that need to be in place, including standards and policies, resources, champions for change, supportive organizational climate and effective knowledge transfer strategies) and encouraging them to incorporate this knowledge into their organizational structure and philosophy for performance improvement. Further application and evaluation of this tool will inform future development and provide insight into how it can best achieve its goal of enhancing care.

Correspondence may be addressed to: Dr. C. McAiney, McMaster-Geriatric Psychiatry, St. Joseph's Healthcare, CMHS, 100 West 5th St., Hamilton, ON L8N 3K7; tel.: 905-522-1155, ext. 36722; fax: 905-575-3778; e-mail: mcaineyc@mcmaster.ca.

\section{NOTES}

1. Additional members of the Healthy and Safe Places to Live and Work Collaborative Group: Jennifer Barr, Program Consultant, Policy, Education and Health Promotion, Centre for Addiction and Mental Health; Patricia Boucher, Vice President, Ontario Safety Association for Community and Healthcare; Catherine Brookman, Director, Special Projects, Ontario Community Support Association; Josie d'Avernas, Associate Director, Schlegel-University of Waterloo Research Institute of Aging; Susan Furino, Program Consultant, Ontario Ministry of Health and Long-Term Care; Pam Hamilton, Psychogeriatric Resource Consultant, Providence Care; Robin Hurst, Mental Health Clinical Consultant, Saint Elizabeth Health Care; Stephanie Lappan-Gracon, Coordinator, Best Practice Champion Network, Registered Nurses' Association of Ontario; J. Kenneth LeClair, Geriatric Psychiatrist, Providence Care; Lori Schindel Martin, Associate Professor, School of Nursing, Ryerson University; Barb McCoy, Psychogeriatric Resource Consultant, Alzheimer Society of Hamilton and Halton; Maureen Montemuro, Clinical Nurse Specialist, St. Peter's Family of Services; Frances Morton, Knowledge Broker, Alzheimer Knowledge Exchange; Karen Parrage, Alzheimer Knowledge Exchange Coordinator; Karen L. Ray, Knowledge Broker, Seniors' Health Research Transfer Network; Josie Santos, Toronto Region Best Practice Guidelines Coordinator, North York General Hospital Seniors' Health Centre.

2. In Ontario, PRCs serve as educators, consultants and program developers to the LTC sector across the province.

3. BPCs in LTC assist nurses and staff in LTC homes in using best practices and incorporating evidence-based practices into their daily care. Both PRCs and BPCs are funded by the provincial Ministry of Health and Long-Term Care. 
Getting a Bigger Bang for Your Buck: A Collaborative Approach to Enhancing Dementia Education Planning in Long-Term Care Homes

\section{REFERENCES}

American Geriatrics Society and American Association for Geriatric Psychiatry. 2003."The American Geriatrics Society and American Association for Geriatric Psychiatry Recommendations for Policies in Support of Quality Mental Health Care in US Nursing Homes." Journal of the American Geriatrics Society 51: 1299-1304.

Aylward, S., P. Stolee, N. Keat and V. Johncox. 2003. "Effectiveness of Continuing Education in Long-Term Care: A Literature Review." Gerontologist 43: 259-71.

Bero, L.A., R. Grilli, J.M. Grimshaw, E. Harvey, A.D. Oxman and M.A. Thomson on behalf of the Cochrane Effective Practice and Organization of Care Review Group. 1998. "Closing the Gap between Research and Practice: An Overview of Systematic Reviews of Interventions to Promote the Implementation of Research Findings." British Medical Journal 317: 465-68.

Berta, W., G.F. Teare, E. Gilbart, L.S. Ginsburg, L. Lemieux-Charles, D.A. Davis and S. Rappolt. 2005. "The Contingencies of Organization Learning in Long-Term Care: Factors that Affect Innovation Adoption." Health Care Management Review 30: 282-92.

Berwick, D.M. 2003. "Disseminating Innovations in Health Care." Journal of the American Medical Association 289: 1969-75.

Bradley, E. H., E.S. Holmboe, J.A. Mattera, S.A. Roumanis, M.J. Radford and H.M. Krumholz. 2003. "The Roles of Senior Management in Quality Improvement Efforts: What Are the Key Components?” Journal of Healthcare Management 48(1): 15-29.

Braun, U.K. and M.E. Kunik. 2004."Behavioral Disturbances in Dementia: Finding the Cause(s)." Geriatrics 59: 32-33.

Broad, M.L. and J.W. Newstrom. 1992. Transfer of Training. Action-Packed Strategies to Ensure High Payoff from Training Investments. Reading, MA: Perseus Books.

Brodaty, H., B. Draper, D. Saab, L.F. Low, V. Richards, H. Paton and D. Lie. 2001."Psychosis, Depression, and Behavioural Disturbances in Sydney Nursing Home Residents: Prevalence and Predictors." International Journal of Geriatric Psychiatry 16: 504-12.

Brookman, C. 2007. The Personal Support Worker Improving Work Experience - A Comparison across Two Health Care Sectors. Unpublished doctoral dissertation, University of Toronto, Ontario.

Canadian Study of Health and Aging Working Group. 1994. "Canadian Study of Health and Aging: Study Methods and Prevalence of Dementia." Canadian Medical Association Journal 150: 899-912.

Endsley, S., M. Kirkegaard and A. Linares. 2005. “Working Together. Communities of Practice in Family Medicine." Family Practice Management 12(1): 28-32.

Ermshoff, J.G., A.J. Darnell, D.A. Darnell, S.W. Erickson, S. Schneider and R. Hudgins. 2007. "Systems Changes as an Outcome and a Process in the Work of Community Collaboratives for Health." American Journal of Community Psychology 39(3-4): 255-67.

Fitzpatrick, P.G. 2002. “Turnover of Certified Nursing Assistants: A Major Problem for LongTerm Care Facilities." Hospital Topics 80(2): 21-25.

Graham, K. and J. Logan. 2004. “Using the Ottawa Model of Research Use to Implement a Skin Care Program.” Journal of Nursing Care Quality 19: 18-24.

Grol, R. and J. Grimshaw. 2003. "From Best Evidence to Best Practice: Effective Implementation of Change in Patients' Care." The Lancet 362: 1225-30. 
Health Professions Regulatory Advisory Council. 2006. Health Professions Regulatory Advisory Council Regulation of Health Professions in Ontario: New Directions. Retrieved October 17, 2009. $<$ http://www.health.gov.on.ca/english/public/pub/ministry_reports/new_directions/new_directions.pdf $>$.

Hogan, D. L. and Logan, J. 2004. The Ottawa Model of Research Use. A Guide to Clinical Innovation in the NICU. Clinical Nurse Specialist 18: 255-61.

Lathlean, J. and A. le May. 2002. "Communities of Practice: An Opportunity for Interagency Working." Journal of Clinical Nursing 11(3): 394-98.

Marsteller, J.A., S.M. Shortell, M. Lin, P. Mendel, E. Dell, E. Wang, S. Cretin, M.L. Pearson, S.Y. Wu and M. Rosen. 2007. "How Do Teams in Quality Improvement Collaboratives Interact?" Joint Commission Journal on Quality and Patient Safety 33: 267-76.

McAiney, C.A., P. Stolee, L.M. Hillier, D. Harris, P. Hamilton, L. Kessler, V. Madsen and J.K. Le Clair. 2007."Evaluation of the Sustained Implementation of a Mental Health Learning Initiative in Long-Term Care." International Psychogeriatrics 19(5): 842-58.

Moule, P. 2006. "E-Learning for Healthcare Students: Developing the Communities of Practice Framework." Journal of Advanced Nursing 54(3): 370-80.

Øvretveit, J., P. Bate, P. Cleary, S. Cretin, D. Gustafson, K. McInnes, H. McLeod, T. Molfenter, P. Plsek, G. Robert, S. Shortell and T. Wilson. 2002. "Quality Collaboratives: Lessons from Research." Quality and Safety in Health Care 11(December): 345-51.

Rummler, G.A. and A.P. Brache. 1990. Improving Performance: How to Manage the White Space on the Organization Chart. San Francisco: Jossey-Bass.

Rummler, G.A. and A.P. Brache. 1995. Improving Performance. (2nd ed.) San Francisco: JosseyBass.

Rushmer, R., D. Kelly, M. Lough, J.E. Wilkinson and H.T.O. Davies. 2004a."Introducing the Learning Practice - I. The Characteristics of Learning Organizations in Primary Care." Journal of Evaluation in Clinical Practice 10(3): 387-98.

Rushmer, R., D. Kelly, M. Lough, J.E. Wilkinson and H.T.O. Davies. 2004b. “Introducing the Learning Practice - III. Leadership, Empowerment, Protected Time and Reflective Practice as Core Contextual Conditions." Journal of Evaluation in Clinical Practice 10(3): 399-405.

Sandars, J. and R. Heller. 2006. "Improving the Implementation of Evidence-Based Practice: A Knowledge Management Perspective." Journal of Evaluation in Clinical Practice 12(3): 341-46.

Scalzi, C.C., L.K. Evans, A. Barstow and K. Hostvedt. 2006."Barriers and Enablers to Changing Organizational Culture in Nursing Homes." Nursing Administration Quarterly 30: 368-72.

Stolee, P., J. Esbaugh, S. Aylward, T. Cathers, D.P. Harvey, L.M. Hillier, N. Keat and J. Feightner. 2005. "Factors Associated with the Effectiveness of Continuing Education in Long-Term Care." Gerontologist 45(3): 399-26.

Tolson, D., I. Schofield, J. Booth, T.B. Kelly and L. James. 2006. "Constructing a New Approach to Developing Evidence-Based Practice with Nurses and Older People." Worldviews on Evidence-Based Nursing 3(2): 62-72.

Watkins, K.E. and V.J. Marsick. 1993. Sculpting the Learning Environment. Lessons in the Art and Science of Systemic Change. San Francisco, CA: Jossey-Bass Pub.

Wenger, E. 1998. Communities of Practice: Learning, Meaning and Identity. Cambridge: Cambridge University. 